\title{
Religion, Spirituality, and the Practice of Medicine
}

\author{
Timothy P. Daaleman, DO
}

Physicians are confronted with new information from the popular media, peer-reviewed journals, and their patients regarding the association of religious and spiritual factors with health outcomes. Although religion and spirituality have become more visible within health care, there are considerable ethical issues raised when physicians incorporate these dimensions into their care. Spiritualities are responsive to patient needs by offering beliefs, stories, and practices that facilitate the creation of a personally meaningful world, a constructed "reality" in the face of illness, disability, or death. It is largely through narrative that physicians incorporate into the health care encounter the spiritualities that are central to their patients' lived experience of illness and health. ( $\mathrm{J}$ Am Board Fam Pract 2004;17: 370-6.)

"Not a week passes in the practice of the ordinary physician but he is consulted about one or more of the deepest problems in metaphysics and religion-not as a speculative enigma, but as part of human agony."

$$
\text { —Richard C. Cabot, } 1918^{1}
$$

There is hardly a month that passes in which I'm not confronted with new information from the either the popular media or peer-reviewed journals about linkages between religious and spiritual factors and health-related outcomes. A recent Newsweek cover story, ${ }^{2}$ a case conference in $7 A M A,{ }^{3}$ and an original research report from the fournal of the American Board of Family Practice ${ }^{4}$ represent a growing awareness of religion and spirituality within health care settings in the United States. Indeed, some forecasters have gone beyond simply recognizing this visibility by projecting the adoption of a health view that will be more inclusive than our current understanding, a global perspective that places spiritual factors alongside physical, psychological, and social determinants. ${ }^{5}$

Submitted, revised, 15 June 2004.

From the Department of Family Medicine, University of North Carolina, Chapel Hill. Address correspondence to Timothy P. Daaleman, DO, Department of Family Medicine, University of North Carolina at Chapel Hill, Campus Box 7595, Manning Drive, Chapel Hill, NC 27599-7595 (e-mail: tim_daaleman@med.unc.edu).

This work was supported by the National Institutes of Health/National Institute on Aging (grant 1K23-AG0103301A1) and the Fetzer Institute.
Two current phenomena validate this forecast of spiritually inclusive health. The first is a burgeoning research interest to explore the process and efficacy of religion and spirituality through medical models and is best represented by the emerging field of psychoneuroimmunology. ${ }^{6}$ Researchers at the University of Pennsylvania have used single photon emission computed tomography (SPECT) to image the brains of meditating Buddhists and Franciscan nuns and have observed localized neural activity during this practice. ${ }^{7}$ The interpretation of these findings - that religious impulses and mystical experiences are reproducible and biologically observable events in the brain - has led to the birth of a new discipline, neurotheology. ${ }^{8}$ Although much of this research is provocative, the logical progression and implications of this area of inquiry troubles me both as a clinician and as a person of faith. Will any experience of God, or what is held to be sacred, be reduced to our gray matter, our neurons, or ultimately our genetic make-up?

One consequence of this overly deterministic orientation, prevalent in biomedical research today, is a largely patient-driven trend to understand and frame the illness experience in more holistic ways that are inclusive of religion and spirituality. ${ }^{9}$ Many physicians have customarily considered physical, psychological, social, and spiritual elements as separate components constituting the human condition. However there is a growing awareness in treating the whole person by viewing health and disease through the integration of mind, body, and spirit largely within the context of family and com- 
munity. ${ }^{10}$ Anthropologists often refer to explanatory models (EMs) as ways in which a patient collectively appraises all these factors to interpret and understand their health and illness. ${ }^{11}$ Although there is a rich tradition of incorporating religious and spiritual perspectives into patient EMs, particularly when suffering is involved, ${ }^{12}$ physician narratives are becoming more remarkable in a language and orientation that touches on the religious and spiritual. ${ }^{13}$ For example, a prominent AIDS and cancer researcher has authored a best-selling collection of stories with the subtitle, "a spiritual exploration of illness." 14

For some academics, both of these movements mark the emergence of a new way to practice medicine that not only considers, but is actively responsive to, the needs of body and spirit. ${ }^{15}$ However, many nonphysicians view such a paradigm with skepticism and raise considerable ethical questions regarding the incorporation of spiritual and religious matters into medical care. ${ }^{16}$ For the ordinary physician like myself, the primary challenge lies not only in how I grasp the nuances and complexities of spirit and belief in my patients and within myself, but also how we-the patient and I-negotiate the movements of this unique human dimension across health and illness. One illustrative example is a 69-year-old patient of mine named Mary (her name has been changed to protect her confidentiality) who was newly diagnosed with an aggressive colon cancer and reported feeling hopeless during a follow-up visit. After my history-taking and physical examination, I struggled with how to interpret and frame her hopelessness. Is Mary's disclosure simply a symptom of depression, or is it a concomitant part of her illness trajectory? ${ }^{17}$ Is it representative of a larger, as-yet-undisclosed religious or spiritual problem? ${ }^{18}$ If so, should I probe for further information? From a treatment standpoint, should I initiate antidepressant therapy or, if Mary reveals a religious or spiritual issue, recommend an intervention that has been clinically proven to be effective? ${ }^{19}$

These are normative and ethical issues for any clinician, and they begin to highlight the nuanced distinction between religion and spirituality. I would first like to clarify this distinction and to view the complex interplay of religion, spirituality, and clinical practice through a social framework, before considering an ethical paradigm. Religion is associated with various connotations: the totality of belief systems; an inner piety or disposition; an abstract system of ideas; and ritual practices. ${ }^{20} \mathrm{Re}-$ ligious doctrine and traditions provide a foundation for understanding the totality of human experience, primarily for communities of faith. Although spirituality also has many connotations, theologian John Shea introduces the term spiritualities as sets of beliefs, stories, and practices that respond to a basic human desire to find meaning and purpose in an integrated way. ${ }^{21}$ These beliefs, stories, and practices may or may not be linked to religious beliefs, practices, or communities. ${ }^{22}$ Within clinical settings, spiritualities are often made manifest in patients who seek to make sense of their illness experience and in caregivers who seek to be attentive to the needs of the whole person. To further understand the phenomenon of religion and spirituality in clinical practice, however, it is useful to consider 3 social perspectives: 2 movements that have legitimized religion and spirituality in health care; the belief and illness experience of the contemporary patient; and the physician's social role within the patient-physician encounter.

\section{Movements to Legitimacy}

The accelerated interest and recognition of spirituality and religion by health care researchers, educators, providers, and consumers have been building for over 15 years. $^{23}$ But 2 parallel, patient-centered movements-end-of-life care and complementary and alternative medicine-have contributed to the legitimacy of religion and spirituality in American health care. Both may be seen as an impetus to rehumanize a system of medical care that has become increasingly impersonal, spiritually barren, and grounded in technology. The current momentum to improve end-of-life care is understandably inclusive of spiritual and religious factors, despite the lack of consistency in how religion and spirituality are addressed in clinical settings. ${ }^{24}$ For example, a report from the Commonwealth-Cummings project lists patient spiritual and existential beliefs as an independent modifiable dimension of the patient's dying experience, ${ }^{25}$ whereas guidelines for palliative care from the Institute of Medicine embed a spiritual assessment as a measure of the patient's emotional status. ${ }^{26}$

Complementary and alternative medicine (CAM) has also promoted a rapprochement between religion, spirituality, and medical practice, 
yet holds a conflicted perspective on the place of religion and spirituality within its armamentarium. Studies that have examined the prevalence and patterns of CAM usage vary in their assignment of alternative spiritual interventions-such as faith healing and prayer-either as a therapeutic modality or as a conventional religious or spiritual ritual that is exclusive of CAM. In 1993, a widely publicized survey on unconventional therapies found that $25 \%$ of respondents acknowledged using prayer as a medical modality. ${ }^{27}$ A 5 -year follow-up study by the same investigators documented an increase in the use of self-prayer and a prevalence of spiritual healing as a common therapy for anxiety, depression, and lung problems. ${ }^{28}$ In a recent analysis of this data, one third of US adults surveyed were found to use prayer for health concerns, both for wellness and for illnesses characterized by painful or aggravating symptoms, nonspecific diagnoses, and limited treatment options such as depression, headaches, and back and/or neck pain. ${ }^{29}$ In addition, high levels of perceived helpfulness, or efficacy, were reported by respondents who used prayer for their health concerns. ${ }^{29}$

\section{A Patient View of Belief, Illness, and Meaning}

The conflicted position of religion and spirituality in end-of-life care and CAM reflects a larger social climate that is ambiguous on the place of religion and spirituality in the practice of medicine. Popular polls are supportive of these CAM findings regarding prayer because most Americans continue to hold positive attitudes and beliefs about its efficacy in healing, although they remain uncertain about religion and spirituality in the medical encounter. A USA Weekend poll found that $79 \%$ of respondents believe that spiritual faith can help people recover from disease, but only $56 \%$ said that their faith had actually helped in their recovery. ${ }^{30} \mathrm{~A}$ more recent multicenter survey found that a only a minority of primary care outpatients preferred that physicians address religion and spirituality during routine office visits. $^{32}$ The study also found that context was an important factor because patients desired greater physician involvement with their spiritual and religious concerns when the severity of their illness increased (ie, when hospitalized or near death). ${ }^{32}$

Studies on a more individual level clarify some of the inconsistencies in these findings. When asked to describe spirituality in the context of well-being, patients in focus group interviews depicted positive thinking and self-efficacy beliefs, and agency beliefs or their use of power or influence. ${ }^{33}$ Agency beliefs are empowering beliefs, viewing people as active participants constructing their own life course through the actions that they take. ${ }^{34}$ Focus group participants also outlined an ongoing process of finding meaning in the face of illness and of placing their illness experience within a larger life context. These qualitative data substantiate one conceptualization of spirituality as a capability to construct an empowering interpretative framework-an explanatory model so to speak - through which health, illness, and life events are viewed. One patient eloquently captured this lattice of meaning and selfidentity as "that kind of harmonious blending of the entire." 34

Yet if religion and spirituality are tied to individual systems of empowered meaning, what is the link between the lived experience of the patient and the larger culture that shapes the illness experience? ${ }^{35}$ Anthony Giddens provides a useful theoretical orientation for integrating the individual perspectives and social currents found in these surveys and narratives. Giddens, a sociologist, posits that maintaining self-identity is an ongoing process of selecting and editing our own individual narratives amid a diversity of options and possibilities. ${ }^{36}$ Self-identity provides us with a sense of control or mastery in day-to-day activities, but when there are threats to self-identity and personal meaning, our individual biographies are reconfigured and reconstructed. ${ }^{37}$

Returning to Mary, the diagnosis and impending treatment of cancer have already confronted her with the specter of a chronic or life-limiting illness, a functional limitation, or a compromised quality of life, all threats to her self-identity. Within this context, spirituality may be conceptualized as how she begins to integrate her illness experience within her larger life course and how well this meaning making empowers her to live her life. Yet she arrives at this point with a lifetime of accumulated beliefs, stories, and practices, her background spiritualities. ${ }^{21}$ Many of these spiritualities will be linked with an identified religious or faith tradition; some will not. But all Mary's background spiritualities are responsive to the current threat to self by offering beliefs, stories, and practices that provide a template for the ongoing creation of a personally 
meaningful world, a constructed empowered "reality" in the face of her current illness. Mary's constructed world will be manifested by her beliefs, stories, and practices that have been transformed by this experience, her foreground spiritualities. ${ }^{21}$ More importantly, her constructed sense of self is contingent on the actions and interactions she maintains in a larger social world, with her family and friends, and with me as her physician. ${ }^{38}$

\section{The Physician's Social Role}

As a physician, I occupy the role of expert within the patient-physician relationship because of my specialized knowledge and skill. ${ }^{37}$ Beyond the technical task of diagnosing and treating disease, I am also responsible for being attentive to my patients' social milieu and for providing information within the context of their illness experience. ${ }^{39}$ It is through my clinical impressions and in the recommendation of selected therapeutic interventions that I convey cultural scripts and suggest illness trajectories to patients and family members. This is a unique social role for physicians. Mary's disclosure of hopelessness, for example, may be framed in a traditional medical model by my assessment of a major depressive episode and consultation with a psychiatrist. However, if Mary's hopelessness results in her decision to forego aggressive treatment, I may view her choice of care as the beginning of a more active dying process and possibly recommend hospice care.

There is inherent power that every physician holds by virtue of possessing a specialized knowledge of diagnosis, prognosis, and treatment. ${ }^{40} \mathrm{Im}$ plicitly or explicitly, we wield power through our frameworks and in the selection of cultural scripts and illness trajectories that we present to patients. But in every clinical context, patients may choose to either incorporate or discard these scripts as they construct or reconstruct their self-identities. ${ }^{37}$ In any event, the resultant clinical narratives are stories of a therapeutic activity facilitated and cocreated by the spiritualities of both patient and physician over time. Larger cultural and social factors within and outside of these clinical encounters are also embedded within this activity. ${ }^{41}$ Factors such as race/ethnicity, social support, education, gender, and religion may be key parts of the scaffolding in the construction of a meaningful world in face of illness, disability, or death. Religious traditions, for example, provide an important ethical foundation for decision making in many areas, such as physician-assisted suicide and end-of-life care. ${ }^{42}$

Sustained clinical narratives that are cocreated by both patient and physician spiritualities may be therapeutic for physicians as well. Patient care not only engages us as experts but also presents the concurrent challenge of maintaining our own personally meaningful world. As physicians, our life's work confronts and sometimes threatens our sense of self through the disability, serious illness, or death of those we care for. Yet the spiritualities offered through patient narratives can contribute to the ongoing construction of our own self-identities by presenting and affirming the human condition in its entirety. For some physicians, spiritualities may be inclusive of practices that are common to patients, such as prayer, reflection and self-awareness. ${ }^{43}$ For others, spiritualities may arise as philosophical or religious belief systems; beliefs that may be held or shared with their patients, beliefs that provide a foundation of purpose for our work. ${ }^{44}$ However, for all physicians, spiritualities that are brought forth by patient stories, and are woven into our own ongoing narratives, are responsive to a basic human desire of finding meaning in an integrated way.

\section{An Ethical Paradigm of Spirituality}

Spiritualities-those beliefs, practices, and stories that respond to a shared human need for meaning-are generated from our social actions and interactions. The lived social worlds of patient and physician intersect during the clinical encounter, the central activity within medicine that defines the moral obligations of physicians. ${ }^{45}$ Both patient and physician arrive at this moment with a lived history that is grounded in the social and cultural, and these frameworks-which are external to medicine-include moral imperatives, because they specify what ought to be done to achieve health and healing. ${ }^{46}$ The ethical challenge of intersecting patient and physician spiritualities lies in how both negotiate these movements across health and illness.

At the onset, any paradigm must be congruent with ethical principles that guide other aspects of clinical practice. ${ }^{47,48}$ However the concept of power-the empowering agency beliefs of the patient and the power that physicians wield through 
illness scripts and trajectories-is basic to understanding and ethically considering spirituality in clinical practice. Howard Brody suggests several guidelines for the ethical use of power within the clinical encounter. ${ }^{40}$ First, physician and patient should use all their power to effect a good patient outcome that is determined by the patient's definition of the presenting problem, and by a contextual understanding of the patient's life course. ${ }^{40}$ In discussing Mary's diagnosis and treatment, I have become aware that she sees cancer as more threatening to her ability to work and remain productive-a source of her agency beliefs-than as a death threat. This helps us both to define the primary good outcome at this time.

Brody goes on to recommend that physicians should share their power by informing the patient about the nature and treatment of the disease. ${ }^{40} \mathrm{I}$ would go further and extend this exchange by including the physician's contextual interpretation of illness as templates and trajectories during the disclosure. Physician power is shared when more than one template is introduced, because patients are free to incorporate or discard any proposed template. Mary's disclosure of hopelessness is illustrative. After reflecting back her comment, I was aware that she had been treated for depression in the past and acknowledged that hopelessness was sometimes an indication of depression; one template was offered. Another template focused on my recollection that Mary had been divorced for some time and had never mentioned her family during any clinic visit. I reflected that the diagnosis of cancer can leave us feeling alone and hopeless, often generating a need for reconciliation with either ourselves, with those close to us, or sometimes with God.

Patient agency beliefs may be inclusive of specific tenets of faith or practices from religious traditions. A belief in healing or prayer comes immediately to mind. Brody suggests that physicians should be supportive of these sources of patient empowerment, as long as they are consistent with a good outcome and are congruent with the patient's goals and interests. ${ }^{40}$ If Mary discloses that prayer is efficacious for her goal of getting to work each day, I need to acknowledge that belief and not seek to substantiate it with clinical evidence. ${ }^{49}$ However, if a conflict arises between the patient's use of power and those ends, it should be handled with negotiation and persuasion and with concern for the patient's vulnerability. ${ }^{50}$

\section{Final Comments}

Brody closes his recommendations with a clinical dictum that physicians should regard the physicianpatient relationship as a primary therapeutic tool. ${ }^{40}$ This therapeutic tool holds true for both for physicians and patients. It is through narrative that physicians begin to palpate the spiritualities- the stories, beliefs, and practices - that reside outside of medicine but are central to our patients and our own lived experience of illness and health. In the context of our ongoing relationships with patients, spiritualities empower us to negotiate this terrain by facilitating and maintaining an entree into the patient world. This normative and moral activity of spirituality lays the foundation for a common ground of a greater and sustained therapeutic activity for both patient and physician. And it is here where the purpose and goals of medicine are fashioned and refashioned. ${ }^{46}$

But this common ground of patient and physician is a place filled with a creative, transformative tension. As Mary and I journey on together, we have no idea how our story will unfold. However, I do know that I have already been changed in some way and sense that she has been as well. This tension reinforces for me that the practice of medicine is a basic social enterprise, a human interaction in which meaningful stories of health and illness are cocreated by patient and physician. It is a tension where I dwell as an "ordinary physician," the nexus between the scientist who seeks to advance the human condition and the clinician who shares the lived experience of the patient. And it is a wondrous tension that recognizes the limits of human medicine but the limitless human spirit.

I thank G. Gayle Stephens, MD, and an anonymous reviewer for their comments on earlier versions of this manuscript.

\section{References}

1. Cabot RC. Training and rewards of the physician. Philadelphia: JB Lippincott; 1918.

2. Kalb C. Faith and healing. Newsweek 2003 Nov $10 ; 44-56$.

3. Koenig HG. An 83-year old woman with chronic illness and strong religious beliefs. JAMA 2002;288: 487-93. 
4. Cooper-Effa M, Blount W, Kaslow N, Rothenberg $\mathrm{R}$, Eckman J. Role of spirituality in patients with sickle cell disease. J Am Board Fam Pract 2001;14: 116-22.

5. Institute for the Future. Health and health care 2010, the forecast, the challenge. San Francisco: Jossey-Bass; 2000.

6. Woods TE, Antoni MH, Ironson GH, Kling DW. Religiosity is associated with affective and immune status in symptomatic HIV-infected gay men. J Psychosom Res 1999;46:165-76.

7. Newberg A, D'Aquili EG, Rause V. Why God won't go away: brain science and the biology of belief. New York: Ballentine; 2001.

8. Begley S. Religion and the brain. Newsweek 2001 May 7;50-57.

9. Furnham A. Explaining health and illness: lay perceptions on current and future health, the causes of illness, and the nature of recovery. Soc Sci Med 1994;39:715-25.

10. Graham R, Bagley B, Kilo CM, Spann SJ, Bogdewic SP. Task Force 1. Report of the task force on patient expectations, core values, reintegration, and the new model of family medicine. Ann Fam Med 2004;2: S33-S50.

11. Kleiman A. The illness narratives. New York: Basic Books; 1988.

12. Tolstoy L. The death of Ivan Ilyich. New York: Bantam; 1981.

13. Geiderman JM. Faith and doubt. JAMA 2000;283: 1661-2.

14. Groopman J. The measure of my days, a spiritual exploration of illness. New York: Penguin; 1997.

15. Koenig HG, McCullough ME, Larson DB. Handbook of religion and health. New York: Oxford Univ Press; 2001.

16. Sloan RP, Bagiella E, VandeCreek L, et al. Should physicians prescribe religious activities? $\mathrm{N}$ Engl J Med 2000;342:1913-6.

17. Breitbart W, Rosenfeld B, Pessin H, et al. Depression, hopelessness, and desire for hastened death in terminally ill patients with cancer. JAMA 2000;284: 2907-11.

18. American Psychiatric Association. Diagnostic and statistical manual of mental disorders, 4th ed. Washington DC: American Psychiatric Association; 1994.

19. Moorey S, Greer S, Bliss J, Law M. A comparison of adjuvant psychosocial therapy and supporting counseling in patients with cancer. Psychooncology 1998; 7:218-28.

20. Wulff DM. Psychology of religion: classic and contemporary. New York: John Wiley \& Sons; 1997.

21. Shea J. Spirituality and health care, reaching toward a holistic future. Chicago: The Park Ridge Center; 2000.

22. Van Ness PH. Spirituality and the secular quest. New York: Continuum; 1996.
23. Matthews DA, McCullough ME, Larson DB, Koenig HG, Swyers JP, Milano MG. Religious commitment and health status. Arch Fam Med 1998; $7: 118-24$.

24. Daaleman TP, VandeCreek L. Placing religion and spirituality in end-of-life care. JAMA 2000; 284:2514-7.

25. Emanuel EJ, Emanuel LL. The promise of a good death. Lancet 1998;351:SII21-9.

26. Institute of Medicine. Approaching death: improving care at the end-of-life. Washington DC: National Academy Press; 1997.

27. Eisenberg DM, Kessler RC, Foster, Norlock FE, Calkins DR, Delbanco TL. Unconventional medicine in the United States: prevalence, costs, and patterns of use. N Engl J Med 1993;328:246-52.

28. Eisenberg DM, Davis RB, Ettner SL, et al. Trends in alternative medicine use in the United States, 1990-1997. JAMA 1998;280:1569-75.

29. McCaffrey AM, Eisenberg DM, Legedza ATR, Davis RB, Phillips RS. Prayer for health concerns: results of a national survey on prevalence and patterns of use. Arch Intern Med 2004;164:858-62.

30. McNichol $\mathrm{T}$. The new faith in medicine. USA Weekend 1996 Apr 5-7;4-5.

31. Deleted in proof.

32. MacLean CD, Susi B, Phifer N, et al. Patient preferences for physician discussion and practice of spirituality. J Gen Intern Med 2003;18:38-43.

33. Daaleman TP, Cobb AK, Frey BB. Spirituality and well-being: an exploratory study of the patient perspective. Soc Sci Med 2001;53:1503-11.

34. Bandura A. Self-efficacy, the exercise of control. New York: WH Freeman; 1997.

35. Kleinman A, Eisenberg L, Good B. Culture, illness, and care, clinical lessons from anthropologic and cross-cultural research. Ann Intern Med 1978;88: 251-8.

36. Giddens A. Modernity and self-identity. Stanford (CA): Stanford University Press; 1991.

37. Giddens A. The constitution of society. Berkeley (CA): University of California Press; 1984.

38. Berger P. Luckmann T. The social construction of reality. New York: Doubleday; 1967.

39. Mechanic D. Medical sociology. New York: Free Press; 1978.

40. Brody H. The healer's power. New Haven: Yale University Press; 1992.

41. Delvecchio Good MJ, Good BJ. Clinical narratives and the study of contemporary doctor-patient relationships. In: Albrecht GL, Fitzpatrick R, Scrimshaw $\mathrm{SC}$, editor. The handbook of social studies in health \& medicine. London: Sage Publications; 2000. p. 243-58.

42. O'Connell LJ. Religious dimensions of dying and death. West J Med 1995;163:231-5. 
43. Epstein RM. Mindful practice. JAMA 1999;282: 833-9.

44. Saba GW. What do family physicians believe and value in their work? J Am Board Fam Pract 1999;12: 206-13.

45. Pellegrino, ED. Philosophy of medicine: should it be telelogically or socially construed? Kennedy Inst J Ethics 2001;11:169-80.

46. Veatch RM. The impossibility of a morality internal to medicine. J Med Philos 2001;26:621-42.

47. Beauchamp TL, Childress JF. Principles of biomed- ical ethics, 4th ed. New York: Oxford University Press; 1994.

48. Pellegrino ED, Thomasma DG. For the patient's good: the restoration of beneficence in health care. New York: Oxford University Press; 1988.

49. Astin JA, Harkness E, Ernst E. The efficacy of "distant healing": a systematic review of randomized trials. Ann Intern Med 2000;132:903-10.

50. APA Committee on Religion and Psychiatry. Guidelines regarding the possible conflict between psychiatrists, religious commitments, and psychiatric practice. Am J Psychiatry 1990;147:542. 